Nielen, M.M., Assendelft, W.J., Drenthen, A.J., Hombergh, P. van den, Dis, I. van, Schellevis, F.G. Primary prevention of cardio-metabolic diseases in general practice: a Dutch survey of attitudes and working methods of general practitioners. European Journal of General Practice: 2010, 16(3), 139-142

\begin{tabular}{|l|ll|}
\hline Postprint Version & 1.0 & \multicolumn{1}{c}{ ni } \\
\hline Journal website & $\underline{\text { http://informahealthcare.com/doi/abs/10.3109/13814788.2010.501372 }}$ & ni \\
\hline Pubmed link & $\underline{\text { http://www.ncbi.nlm.nih.gov/pubmed/20825271 }}$ \\
\hline DOI & $10.3109 / 13814788.2010 .501372$ \\
\hline
\end{tabular}

This is a NIVEL certified Post Print, more info at http://www.nivel.eu

\title{
Primary prevention of cardio-metabolic diseases in general practice: A Dutch survey of attitudes and working methods of general practitioners
}

\author{
MARKUS M. J. NIELEN ${ }^{1}$, WILLEM J. J. ASSENDELFT ${ }^{2}$, ANTON J. M. DRENTHEN ${ }^{3}$, PIETER \\ VAN DEN HOMBERGH ${ }^{4}$, INEKE VAN DIS ${ }^{5} \&$ FRANCOIS G. SCHELLEVIS ${ }^{1,6}$
}

1 NIVEL (Netherlands Institute for Health Services Research), Utrecht, the Netherlands,

2 Department Public Health and Primary Care, Leiden University Medical Center, Leiden, the Netherlands, 3 Department of Prevention and Patient Education, Dutch College of General Practitioners (NHG), Utrecht, the Netherlands,

4 Dutch National Association of General Practitioners (LHV), Utrecht, the Netherlands,

5 Netherlands Heart Foundation, The Hague, the Netherlands,

6 Department of General Practice/EMGO Institute, VU University Medical Center, Amsterdam, the Netherlands

\begin{abstract}
Background: To study the attitudes and working methods of general practitioners (GPs) in primary prevention of cardiovascular diseases, diabetes mellitus and chronic kidney diseases.

Methods: A questionnaire with questions about attitude and working methods in the primary prevention of cardiovascular diseases, diabetes mellitus and chronic kidney diseases in general practice was sent to a representative sample of 1,100 Dutch GPs. The questionnaire was developed in collaboration with experts in general practice, cardiovascular disease, diabetes and kidney disease.

Results: A total of 330 GPs completed and returned the questionnaire (30\% response). Only a quarter of the GP 's actively invite patients for preventive measurements. Preventive measures are mainly performed by the GP when a patient asks for it or when patients visit a GP for other complaints. The main reasons for performing preventive tests were a positive family history, obesity and smoking. Most GPs consider detection of these diseases as worthwhile, but detection should particularly focus on the group of patients with the highest risk on these diseases.
\end{abstract}

Conclusion: GPs have a positive attitude towards primary prevention of cardiovascular diseases, diabetes mellitus and chronic kidney diseases, but primary prevention should be focused on patients at risk.

Key words: Surveys , prevention , diabetes , heart and circulation

\section{INTRODUCTION}

The prevalence of lifestyle-related diseases is increasing in developed countries. Most important health problems caused by an unhealthy lifestyle are cardiovascular disease, diabetes mellitus and chronic kidney 
Nielen, M.M., Assendelft, W.J., Drenthen, A.J., Hombergh, P. van den, Dis, I. van, Schellevis, F.G. Primary prevention of cardio-metabolic diseases in general practice: a Dutch survey of attitudes and working methods of general practitioners. European Journal of General Practice: 2010, 16(3), 139-142

disease (further described as ' cardio-metabolic diseases ' ). Increasing rates of obesity and smoking will 7 increase the number of patients with cardio-metabolic diseases in the coming decades $(1-3)$. Thereforeivel the need for early detection and integrated treatment of persons with an increased risk for these disorders is growing to prevent future problems for the patient and to reduce the costs for health care. In the Netherlands, general practitioners (GPs) have traditionally been reluctant about their role in primary prevention and are currently only involved in prevention programs for infl uenza vaccination and screening for cervical uterine cancer. However, recent studies have shown that screening for cardio-metabolic disorders could be more effi cient when it is embedded in health care $(4,5)$. The GP could play an important role in prevention of cardiovascular disease, diabetes mellitus and kidney disease, since (1) all Dutch inhabitants are listed with a general practice, and (2) Dutch GPs are already familiar with prevention programs. In the near future, a ' preventive consultation' will be included in the GP services for the integrated primary prevention of cardiovascular disease, diabetes mellitus and chronic kidney disease according to evidence-based guidelines (6). The purpose of this study was to investigate the current attitudes and working methods of GPs in primary prevention of cardiovascular diseases, diabetes mellitus and chronic kidney diseases before the implementation of this preventive consultation.

\section{METHODS}

A random sample of 1.100 GPs was drawn from all listed GPs (about $n=8.600$ ) in the Netherlands in March 2008 (7). In April 2008, the 1100 GPs were sent a written questionnaire with questions about their attitude and working methods regarding primary prevention of cardiovascular disease, diabetes mellitus and chronic kidney disease in general practice. The questionnaire is developed in collaboration with experts in general practice, cardiovascular disease, diabetes mellitus and kidney disease. Questions about attitude and working methods were assessed by using a fi ve-grade Likert scale and recoded to ' Yes ' , Somewhat' and ' No' . Questions about performing a preventive measurement in case of a risk factor were measured on a two-point scale (Yes/No). These questions included not only the traditional risk factors, such as family history of diabetes and/or cardiovascular disease and lifestyle related factors, but also socioeconomic status and ethnicity. Persons with a low socioeconomic status and persons with a specifi c ethnic background have an increased risk for cardiovascular disease, diabetes and kidney disease. An accompanying letter showed the support of the Dutch College of General Practitioners and the Dutch National Association of General Practitioners for the study. After two weeks, a reminder was sent to maximize the response. Frequency Tables were calculated with SPSS 14.0.

\section{RESULTS}

Of the 1,100 approached GPs, 330 GPs completed and returned the questionnaire (30\% response). The characteristics of the respondents and the total random sample of GPs are shown in Table I. The responding GPs had a mean age of 48 years and 61\% were male. Most of the responding GPs worked in a singlehanded or duo practice (31\% and 34\%, respectively). Compared with the total random sample of GPs, the responding GPs had a similar distribution of gender (61\% versus 63\% male) and urbanization level of the location of the general practice (44\% versus $45 \%$ high urbanization level). The responding GPs were older compared to the non-respondents $(\mathrm{P}=0.05$ ), which was caused by an overrepresentation in the age group 50 - 59 years old. GPs were asked to what extent different methods for detecting patients with an increased risk for cardio-metabolic disorders were used in their practice (Table II). 77 responding GPs (24\%) actively invite patients to visit their practice for preventive measurements. 182 GPs (56\%) performed preventive measurements in patients who visit the practice for complaints other than cardio-metabolic complaints. Most the respondents perform preventive measurements for detecting patients with an increased risk of cardio-metabolic diseases when the patient asks explicitly for it (90\%) and when patients are known with risk factors for cardiovascular disease, diabetes mellitus and kidney disease (96\%). Based on the answers on the fi rst two questions in Table II, a distinction was made between GPs who showed a positive or a negative attitude towards active prevention strategies in general practice (positive if both statements were answered with ' yes' ; otherwise it was defi ned as negative). GPs younger than 40 were more positive in comparison to GPs in the age groups $40-49(\mathrm{P}=0.03)$ and $50-59(\mathrm{P}=0.05)$ (data not shown). Table III shows the number of GPs that reported to perform a preventive measurement — blood pressure, lipid profi le, blood glucose and albuminuria — depending on the presence of a risk factor for cardiovascular disease, 
Nielen, M.M., Assendelft, W.J., Drenthen, A.J., Hombergh, P. van den, Dis, I. van, Schellevis, F.G. Primary prevention of cardio-metabolic diseases in general practice: a Dutch survey of attitudes and working methods of general practitioners. European Journal of General Practice: 2010, 16(3), 139-142

diabetes mellitus and/or kidney disease. Preventive measurements are most frequently performed in paient $\$$ with fi rst-degree relatives with cardiovascular diseases and/or diabetes mellitus. Blood pressure, lipidrpiqfel le and blood glucose is measured by more than $90 \%$ of the GPs in patients with these risk factors. A minority of the responding GPs measure albuminuria in these patients. Other risk factors that frequently trigger a preventive measurement are obesity and smoking. Finally, half of the GPs perform preventive blood glucose measurements in patients with a Hindustani background because of their increased risk for diabetes mellitus. Finally, most of the responding GPs consider the detection of patients with an increased risk for cardiovascular disease, diabetes mellitus and chronic kidney disease worthwhile (88\%) and state that early detection can improve the quality of life of these patients (76\%). However, according to the respondents, detection should particularly focus on the group of patients with the highest risk for these diseases (87\%). In addition, most GPs consider the general practice the most important setting to detect patients with an increased risk for cardiovascular disease, diabetes mellitus and chronic kidney disease (94\%). Furthermore, they argue that preventive activities could be well performed by a practice nurse (87\%). A healthy lifestyle can only be advised if there is enough time during a visit (89\%).

[TABLE 1, 2, 3]

\section{DISCUSSION}

The purpose of this study was to investigate the attitude and working methods of GPs in primary prevention of cardiovascular disease, diabetes mellitus and kidney disease before the implementation of a program detecting and treating patients with an increased risk for these disorders in Dutch general practices. Currently, preventive measures are particularly performed by the GP when the patient asks for it during the consultation or when patients visit the GP for other complaints. Only a quarter of the GPs actively invite patients to visit the practice for preventive measurements. Detection should particularly focus on the patients with the highest risk profi le, such as patients with fi rst-degree family members with cardiovascular diseases and/or diabetes mellitus, or patients that are overweight and smokers. The response to the questionnaire was only $30 \%$. Previous studies have shown that GPs are poor responders to surveys $(8,9)$. A low response rate is not problematic as long as the respondents are representative for the target population. Besides a small overrepresentation of GPs in the age category $50-59$ years old, we found no differences between the characteristics of the respondents and the total population of GPs. Therefore, the results of this study can be considered to be representative for the population of practicing GPs in the Netherlands. However, it is possible that there was a selective response of GPs who show a more positive attitude towards integrated primary prevention of cardiovascular diseases, diabetes mellitus and/or kidney diseases. GPs receive many requests to complete questionnaires and they may select the subjects they are interested in (10). Furthermore, we used self-reported data, which could have resulted in socially desirable responding. It is unclear to what extent these latter two factors have biased the results of this study. GPs could play an important role in prevention of cardiovascular disease, diabetes mellitus and kidney disease. Dutch GPs are not only familiar with prevention programs, but also all Dutch inhabitants are listed with a general practice. This is in concordance with the opinion of the responding GPs in this study. We found that most GPs consider the general practice as the most important setting for the primary prevention of these diseases and they considered detection and prevention of cardiometabolic diseases worthwhile. Lack of time could be an important barrier for a successful implementation of prevention programs in general practice $(11,12)$. This problem could be solved when preventive activities are performed by a practice nurse, which was also found in previous research (12). Finally, previous research showed that a lack of organization in general practice may be an obstacle for a successful implementation (13). However, despite the positive attitude of GPs towards primary prevention, it is likely that the implementation of a program for integrated primary prevention of disease, diabetes mellitus and chronic kidney disease could result in considerable changes in the working methods of GPs. Currently only one quarter of the participating GPs actively invite patients to visit their practice for preventive measurements.

\section{CONCLUSION}

It can be concluded that Dutch GPs currently show a positive attitude towards integrated primary prevention of cardiovascular disease, diabetes mellitus and kidney disease, but prevention should be focused on patients at high risk. According to the participating GPs in this study, general practice is the 
Nielen, M.M., Assendelft, W.J., Drenthen, A.J., Hombergh, P. van den, Dis, I. van, Schellevis, F.G. Primary prevention of cardio-metabolic diseases in general practice: a Dutch survey of attitudes and working methods of general practitioners. European Journal of General Practice: 2010, 16(3), 139-142

right care setting for detecting and treating patients with an increased risk for these diseases. Future research will be necessary to demonstrate whether this positive attitude of GPs has enhanced the implementation of the prevention program and whether this program will result in a decrease of the number of patients with cardiovascular disease, diabetes mellitus and chronic kidney disease.

\section{ACKNOWLEDGEMENTS}

The study was funded by Netherlands Heart Foundation, the Dutch Kidney Foundation and the Dutch Diabetes Research Foundation.

\section{DECLARATION OF INTEREST:}

The authors report no conflicts of interest. The authors alone are responsible for the content and writing of the paper.

\section{REFERENCES}

1. King H, Aubert RE, Herman WH. Global burden of diabetes, 1995 - 2025: Prevalence, numerical estimates, and projections. Diabetes Care 1998;21:1414 - 31.

2. Yusuf S, Reddy S, Ounpuu S, Anand S. Global burden of cardiovascular diseases: Part I: general considerations, the epidemiologic transition, risk factors, and impact of urbanization. Circulation 2001;27:2746 - 53 .

3. James WP. The epidemiology of obesity: the size of the problem. J Intern Med. 2008;263:336 - 52.

4. Jongh D de, Dijk L van, Schellevis FG. Vroege opsporing en behandeling van mensen met risicofactoren voor hart - en vaatziekten. Evaluatie van initiatieven. Utrecht: NIVEL; 2007.

5. Nielen MM, Schellevis FG, Verheij RA. The usefulness of a free self-test for screening albuminuria in the general population: a cross-sectional survey. BMC Public Health 2009;9:381.

6. PreventieConsult gaat pilotfase in. Ned Tijdschr Geneeskd. 2009;153:C238.

7. Hingstman L, Kenens RJ: Cijfers uit de registratie van huisartsen. Peiling 2008. Utrecht: NIVEL; 2008.

8. McDonald P. Response rates in general practice studies. Br J Gen Pract. 1993;43:484.

9. McAvoy BR, Kaner EF. General practice postal surveys: a questionnaire too far? Br Med J. 1996;21:732 $-3$.

10. Templeton L, Deehan A, Taylor C, Drummond C, Strang J. Surveying general practitioners: Does a low response rate matter? $\mathrm{Br} J$ Gen Pract. 1997;47:91 - 4.

11. Cornuz J, Ghali WA, Di Carlantonio D, Pecoud A, Paccaud F. Physicians ' attitudes towards prevention: Importance of intervention-specifi c barriers and physicians ' health habits. Fam Pract. 2000;17:535 - 40.

12. Steptoe A, Doherty S, Kendrick T, Rink E, Hilton S. Attitudes to cardiovascular health promotion among GPs and practice nurses. Fam Pract. 1999;16:158 - 63.

13. Hulscher ME, Drenth BB van, Mokkink HG, Wouden JC van der, Grol RP. Barriers to preventive care in general practice: The role of organizational and attitudinal factors. Br J Gen Pract. 1997;47:711 - 4. 
Nielen, M.M., Assendelft, W.J., Drenthen, A.J., Hombergh, P. van den, Dis, I. van, Schellevis, F.G. Primary prevention of cardio-metabolic diseases in general practice: a Dutch survey of attitudes and working methods of general practitioners. European Journal of General Practice: 2010, 16(3), 139-142

\section{TABLES}

\section{[TABLE 1]}

Table I. Characteristics of the respondents and the random sample of GPs.

\begin{tabular}{lcc}
\hline & $\begin{array}{c}\text { Respondents } \\
(n=330)\end{array}$ & $\begin{array}{c}\text { Random } \\
\text { sample of GPs } \\
(n=1100)\end{array}$ \\
\hline Age category & & \\
$<40$ years old (\%) & 21.5 & 18.6 \\
$40-49$ years old (\%) & 26.7 & 30.8 \\
$50-59$ years old (\%) & 44.4 & 39.9 \\
60 years and older (\%) & 7.3 & 10.7 \\
Gender & & \\
Male (\%) & 61.2 & 62.9 \\
Female (\%) & 38.8 & 37.1 \\
Urbanization level of the location of the general practice \\
High (\%) & 43.5 & 44.9 \\
Medium (\%) & 18.3 & 18.9 \\
Low (\%) & 38.2 & 36.2 \\
Type of practice & & - \\
Single-handed & 30.8 & - \\
Duo & 34.1 & - \\
Group & 24.1 & - \\
Health centre & 11.0 & \\
\hline
\end{tabular}


Nielen, M.M., Assendelft, W.J., Drenthen, A.J., Hombergh, P. van den, Dis, I. van, Schellevis, F.G. Primary prevention of cardio-metabolic diseases in general practice: a Dutch survey of attitudes and working methods of general practitioners. European Journal of General Practice: 2010, 16(3), 139-142

[TABLE 2]

Table II. Working methods of GPs to detect patients with an increased risk for cardiovascular disease, diabetes and kidney disease (percentages; $n=330$ ).

\begin{tabular}{|c|c|c|c|}
\hline & \multicolumn{3}{|c|}{ Using this method? } \\
\hline & $\begin{array}{l}\text { Yes } \\
(\%)\end{array}$ & $\begin{array}{c}\text { Somewhat } \\
(\%)\end{array}$ & $\begin{array}{l}\text { No } \\
(\%)\end{array}$ \\
\hline $\begin{array}{l}\text { Actively inviting patients for } \\
\text { preventive measurements }\end{array}$ & 23.6 & 12.2 & 64.2 \\
\hline $\begin{array}{l}\text { Preventive measurements in } \\
\text { patients who visit the general } \\
\text { practice for other complaints } \\
\text { than cardio-metabolic } \\
\text { complaints }\end{array}$ & 55.6 & 19.6 & 24.8 \\
\hline $\begin{array}{l}\text { Preventive measurements when } \\
\text { a patient asks for it }\end{array}$ & 90.0 & 7.3 & 2.7 \\
\hline $\begin{array}{l}\text { Preventive measurements in } \\
\text { patients with risk factors for } \\
\text { cardio-metabolic disorders }\end{array}$ & 96.0 & 2.5 & 1.5 \\
\hline
\end{tabular}


Nielen, M.M., Assendelft, W.J., Drenthen, A.J., Hombergh, P. van den, Dis, I. van, Schellevis, F.G. Primary prevention of cardio-metabolic diseases in general practice: a Dutch survey of attitudes and working methods of general practitioners. European Journal of General Practice: 2010, 16(3), 139-142

\section{[TABLE 3]}

Table III. Percentages of GPs that perform a preventive measurement depending on the presence of a risk factor for cardiovascular disease, diabetes and kidney disease $(n=330$; percentages).

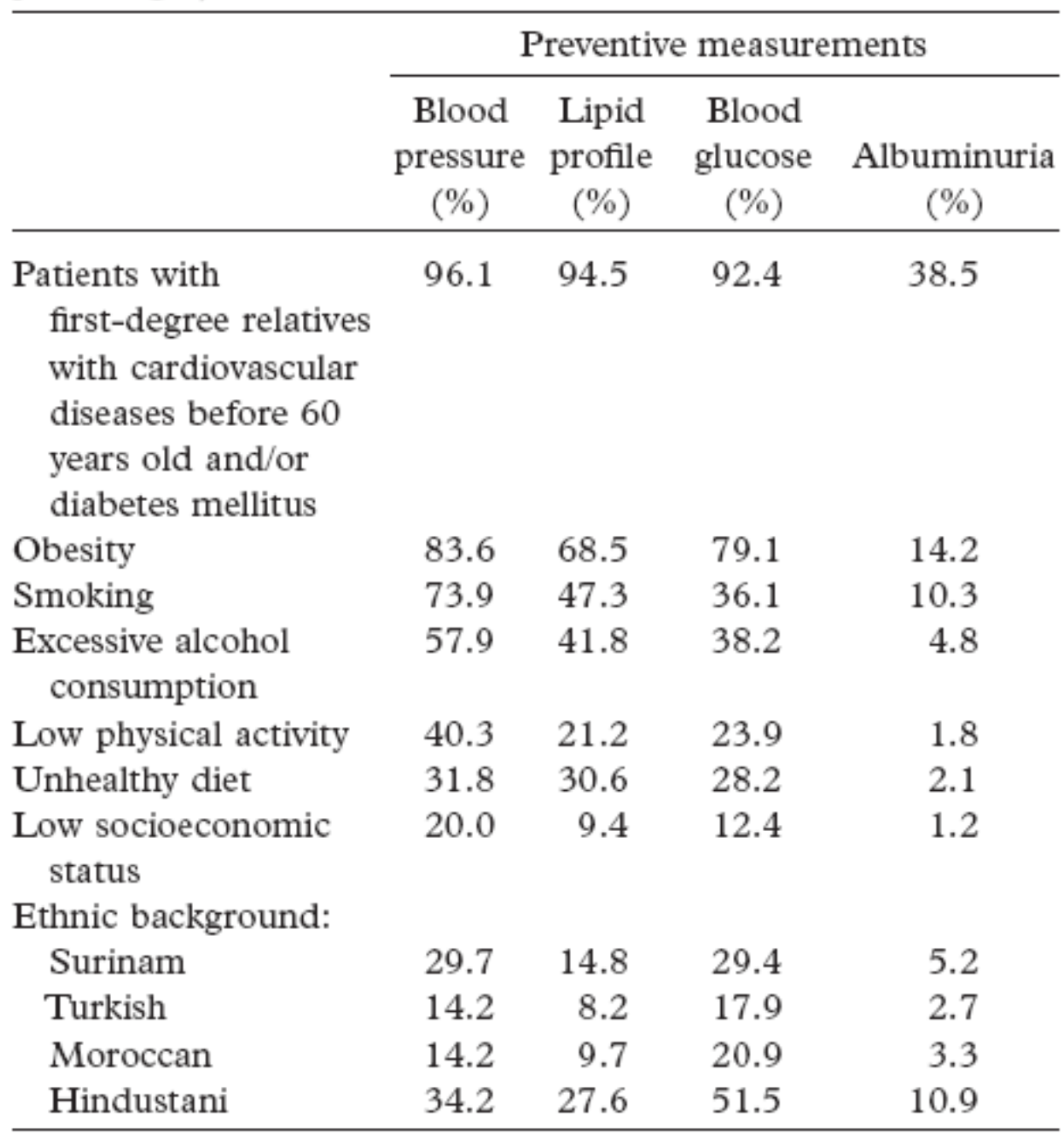

